\title{
Raiva em morcegos insetívoros (Molossidae) do Sudeste do Brasil*
}

\author{
Rabies in insectivorous bats (Molossidae) of southeastern Brazil \\ Wilson Uieda, Necira M. S. Harmani, Miriam M. S. Silva \\ Departamento de Zoologia, Instituto de Biociências, Universidade Estadual Paulista (UNESP) - Botucatu, SP - Brasil \\ (W.U.), Centro de Controle de Zoonoses, Prefeitura de São Paulo - São Paulo, SP - Brasil (N.M.S.H. M.M.S.S.)
}

\begin{abstract}
Quatro casos positivos para a raiva foram diagnosticados em morcegos de três espécies de molossídeos (um Molossus molossus, um Nycthomops laticaudatus e dois $N$. macrotis) do Estado de São Paulo, Brasil. Três defes toram encontrados durante o dia em locais visiveis e nāo habituais $\theta$ o outro entrou pela janela, no início da nolte. Quadro descritivo com 19 casos semelhantes, envolvendo oito espécies, é mostrado e indica que morcegos com comportamento atípico devem ser cons/derados como fortemente suspeitos de estarem doentes, possivelmente com raiva.
\end{abstract}

Raiva, epidemiologia. Quirópteros, microbiologia. Virus da raiva, isolamento.

\section{Introdução}

Os molossídeos são morcegos insetívoros de hábitos gregário e crespucular. Nas regiões temperadas, podem se abrigar em amplas cavernas e formar colônias de milhōes de indivíduos ${ }^{8}$. Nas regiões tropicais, suas colônias sāo menores e contêm dezenas, centenas ou ocasionalmente milhares de morcegos.

Várias espécies de morcegos vivem em ecossistemas urbanos, utilizando recursos fornecidos direta ou indiretamente pelo homem, como edificaçōes, plantas e iluminação noturna. As edifiçōes são usadas geralmente como abrigos diurnos. Algumas espécies de plantas de arborização servem como abrigos (diurnos e/ou notumos), e outras, como fontes de alimento. A iluminação notuma das cidades atrai insetos voadores que são habitualmente comidos por norcegos. Esses mamíferos voadores podem trazer transtornos às pessoas dependendo dos locais em que se abrigam, do tamanho de suas colônias e de possíveis doenças. Constantine ${ }^{4,6}$ compilou as principais doenças associadas direta e/ou indireta- mente aos morcegos. Uma das principais doenças é a raiva, já diagnosticada em várias espécies de morcegos ${ }^{1 ., 6,13}$, inclusive nas de molossídeos.

No presente estudo são relatados quatro casos de raiva em três espécies de molossídeos, as circunstâncias em que foram encontrados e suas possíveis relaçôes com a saúde pública. É apresentado um quadro descritivo de vários casos de raiva em morcegos, com informaçōes biológicas e comportamentais dos mesmos.

\section{Descriçăo dos Casos}

Os quatro casos de raiva em molossídeos foram encontrados no Estado de Sāo Paulo, Sudeste do Brasil, no período de 1988 a 1991 . Para uma análise comparativa, apresentamos uma Tabela contendo 19 casos, envolvendo oito espécies de morcegos, já conhecidos na literatura, e outros não publicados. Os casos aqui descritos são citados, a seguir, em ordem cronológica. 
10 Caso:

Em junho de 1988, o Centro de Controle de Zoonoses de São Paulo (CCZ) foi acionado para capturar um morcego que, por volta das 19:00h, entrou voando pela janela de um apartamento no $7^{\circ}$ andar de um edifício situado na área central da cidade de São Paulo $\left(46^{\circ} 38^{\prime} \mathrm{W}, 23^{\circ} 32^{\prime}\right.$ 'S). $\mathrm{O}$ animal, Nyctinomops macrotis (Gray), foi encontrado locomovendo-se pelo chão e, após sua captura, foi encaminhado ao $\mathrm{CCZ}$ para exames laboratoriais de raiva. $O$ diagnóstico foi positivo nos exames de imunofluorescência direta $\mathrm{e}$ inoculação em camundongos.

No inquérito epidemiológico foi verificado que o provável abrigo do animal doente era um vão de dilatação entre as paredes de prédios lindeiros residenciais, incluindo aquele onde o morcego foi encontrado. Recomendações sobre vedação do abrigo e informações sobre esses animais foram fornecidas às pessoas do prédio. Um dia após a vedação, 11 outros exemplares de $N$. macrotis foram capturados sob o rufo do prédio e, nos exames laboratoriais, foram negativos para a raiva.

O presente estudo é o primeiro registro de raiva em N. macrotis no Brasil.

\section{Caso:}

Em novembro de 1989 , por volta das $14: 00 \mathrm{~h}$, um morcego foi encontrado vivo no chão da calçada de uma rua comercial, área urbana da cidade de Botucatu $\left(48^{\circ} 25^{\prime} \mathrm{W}, 22^{\circ} 55^{\prime} \mathrm{S}\right)$, Estado de São Paulo. Esse morcego, uma fêmea adulta de Molossus molossus (Pallas), estava sendo importunado com auxílio de varas por um grupo de pessoas. Após ser capturado, foi encaminhado para exames de raiva na Faculdade de Medicina Veterinária e Zootecnia da UNESP-Botucatu. $O$ diagnóstico foi negativo na imunofluorescência direta e positivo na inoculação em camundongos.

\section{Caso:}

Em fevereiro de 1990, por volta das 10:00h, um morcego foi localizado pousado no muro de uma casa situada numa rua residencial, área central da cidade de São Paulo. O quiróptero, uma fêmea de Nyctinomops macrotis, foi descoberto pelas crianças da vizinhança e permaneceu vivo $\varepsilon$ imovel até ser capturado pelos técnicos do CCZ. O diagnóstico foi positivo na imunofluorescência direta e na inoculação em camundongos.
No inquérito epidemiológico não foi encontrado seu abrigo diurno e informações gerais sobre morcegos foram fornecidas às pessoas da área.

\section{Caso:}

Em março de 1991, por volta das 7:30h, um morcego foi encontrado imóvel sobre o batente de uma janela de um apartamento no quarto andar de um prédio residencial, área central da cidade de Guarulhos (46 $33^{\prime} \mathrm{W}, 2^{\circ} 28^{\prime} \mathrm{S}$ ) Estado de São Paulo. Ao ser molestado, o animal, uma fêmea de Nyctinomops laticaudatus (E. Geoffroy), "tentou" voar mas caiu no piso do "playground" do condomínio. $\mathrm{O}$ quiróptero moribundo foi capturado e encaminhado ao Instituto Biológico de Săo Paulo, onde foram realizados os exames laboratoriais de raiva. $O$ diagnóstico foi positivo na imunofluorescência direta e inoculação em camundongos.

No inquérito epidemiológico não foi localizado seu abrigo diumo. Informações gerais sobre morcegos e orientação foram fornecidas às pessoas do condomínio residencial.

$O$ presente trabalho representa a primeira ocorrência de raiva diagnosticada em $N$. laticaudatus no Brasil.

\section{Discussão}

Nos quatro casos de raiva, os morcegos foram encontrados, ainda vivos, em locais năo habituais (chão de sala, calçada de rua, muro de casa e batente de janela). Em três dos casos, o horário em que foram encontrados também não era habitual para suas atividades fora dos abrigos: 7:30, 10:00 e 14:00h. Estas características poderiam ser consideradas como um sintoma de estado doentio do animal, possiveimente raiva, como já foi mencionado por alguns autores ${ }^{1,4,5,6}$. Segundo Constantine ${ }^{5}$, cerca de $10 \%$ dos morcegos doentes, mortos ou suspeitos que foram submetidos a exames, na Califórnia (USA), deram resultados positivos para a raiva. $\mathrm{O}$ mesmo autor ${ }^{5}$ verificou que $63 \%$ dos morcegos infectados por raiva $\mathrm{e}$ detectados anualmente estavam paralíticos ou doentes. Nessas situações, as chances de ocorrer agressão humana acidental (envolvendo principalmente crianças) e/ou agressão a animais de estimação (cães e gatos), causada por um morcego raivoso são remotas $s^{5}$, mas não podem ser desprezadas. Os casos de raiva humana, transmitidos por morcegos, nāo são raros e sua transmissāo geralmente ocone por manipulação indevida de animal moribundo ${ }^{5}$. Em um quadro descritivo de 10 
Tabela - Descrição de 19 registros de morcegos encontrados em situaçōes atipicas e com diagnóstico para raiva.

\begin{tabular}{|c|c|c|c|c|}
\hline Espécie & $\begin{array}{l}\text { Data de } \\
\text { captura }\end{array}$ & Local & Observaçōes & Fontes \\
\hline \multicolumn{5}{|c|}{ Morcegos insetivoros } \\
\hline $\begin{array}{l}\text { Nyctinomops } \\
\text { macrotis }\end{array}$ & 12.06 .88 & $\begin{array}{l}\text { Sào Paulo } \\
\text { SP, Brașil }\end{array}$ & $\begin{array}{l}\text { - Entrou em vôo pela janela de apto. do } 7^{\circ} \text { andar às } 19: 00 \mathrm{~h} \text { e foi } \\
\text { encontrado no chăo. Sem agressão humana. }\end{array}$ & $a$ \\
\hline N. macrotis & 18.02 .90 & $\begin{array}{l}\text { Säo Paulo } \\
\text { SP, Brasil }\end{array}$ & $\begin{array}{l}\text { - Encontrado às } 10: 00 \text { h pousado num muro enquanto sendo molestado } \\
\text { por crianças. Sem agressão humana. }\end{array}$ & a \\
\hline N. latrcaudatus & 20.03 .91 & $\begin{array}{l}\text { Guarulhos } \\
\text { SP: Brasil }\end{array}$ & $\begin{array}{l}\text { - Encontrado às } 7: 30 \text { pousado no batente de janela de apto. do } 49 \\
\text { andar. Sem capacidade de vôo e sem agressáo humana. }\end{array}$ & a \\
\hline $\begin{array}{l}\text { Motossus } \\
\text { molossus }\end{array}$ & $\begin{array}{l}24.11 .89 \\
\text { SP, Brasil }\end{array}$ & Botucatu & $\begin{array}{l}\text { - Encontrado as 14:00h pousado na calçada de rua enquanto molestado } \\
\text { por pessoas. Sem agressảo humane. }\end{array}$ & a \\
\hline M. molossus & 17.10 .72 & $\begin{array}{l}\text { Campinas } \\
\text { SP. Brasil }\end{array}$ & $\begin{array}{l}\text { - Capturado em pleno dia no pátio de fazenda, impossibilitado de } \\
\text { voar. Viveu por } 2 \text { dias. Poucos movimentos e excitaçảo aparente. } \\
\text { Sem agressão humana. }\end{array}$ & 9 \\
\hline $\begin{array}{l}\text { Tadarida } \\
\text { brastiensis }\end{array}$ & $? .04 .65$ & $\begin{array}{l}\text { São Leopoldo } \\
\text { RS, Brasıl }\end{array}$ & $\begin{array}{l}\text { - Encontrado no interior de residència, com sintomas de paralisia. } \\
\text { Morreu pouco depols. Sem agressāo humana. }\end{array}$ & 2 \\
\hline$T$. brasiliensis & $? .04 .70$ & $\begin{array}{l}\text { Cordoba } \\
\text { Argentina }\end{array}$ & $\begin{array}{l}\text { Encontrado no chảo, junto à porta da casa. Capturado com } \\
\text { facilidade tendo mordido o dedo de quem o capturou. }\end{array}$ & 10 \\
\hline T. brasiliensis & 1104.54 & $\begin{array}{l}\text { Houston Mit. } \\
\text { Texas, USA }\end{array}$ & $\begin{array}{l}\text { - Pendurado na porta de construçāo. Com paralısıa convulsaiva. Sern } \\
\text { agressão humana. }\end{array}$ & 3 \\
\hline T. brasitrensis & 23.04 .54 & $\begin{array}{l}\text { Houston Mil. } \\
\text { Texas, USA }\end{array}$ & $\begin{array}{l}\text { - Encontrado por soldado, sem dados de captura. Com paralisıa das } \\
\text { asas, retenção de urina, irrıtação e tremores musculares. Sem } \\
\text { agressão humana. }\end{array}$ & 3 \\
\hline$T$. brasifrensis & 27.04 .54 & $\begin{array}{l}\text { Houston Mil. } \\
\text { Texas, USA }\end{array}$ & $\begin{array}{l}\text { - Encontrado por soldado, sem dados de captura. Com paralisia das } \\
\text { asas, retenção de urina, irritação e tremores musculares. Sem } \\
\text { agressăo humana. }\end{array}$ & 3 \\
\hline T. brasillensis & 13.05 .54 & $\begin{array}{l}\text { Houston Mil. } \\
\text { Texas, USA }\end{array}$ & $\begin{array}{l}\text { - Encontrado por soldada, sem dados de captura. Com paralisia das } \\
\text { asas, retençāo de urına, irritaçāo e tremores musculares. Sem } \\
\text { agressão humana. }\end{array}$ & 3 \\
\hline T. brasiliensis & 13.05 .54 & $\begin{array}{l}\text { Houston Mil. } \\
\text { Texas, USA }\end{array}$ & $\begin{array}{l}\text { - Encontrado por soldado, sem dados de captura. Com encefalite } \\
\text { aparente. Sem agressão humana. }\end{array}$ & 3 \\
\hline $\begin{array}{l}\text { Eumops } \\
\text { auripendulus }\end{array}$ & $? ? ?$ & $\begin{array}{l}\text { Misiones } \\
\text { Argentina }\end{array}$ & $\begin{array}{l}\text { - } 5 \text { morcegos capturados no sótäo de escola e um deles com paralisia } \\
\text { evidente e sem capacıdade de vóo. Sem agressảo humana. }\end{array}$ & 7 \\
\hline
\end{tabular}

Morcegos Frugivoros

$\begin{array}{ccll}\begin{array}{c}\text { Artibeus } \\ \text { jamaicensis }\end{array} & 19.09 .88 & \begin{array}{l}\text { Cedral } \\ \text { SP, Brasil }\end{array} & \begin{array}{l}\text { - Pousado num tronco de árvore durante o dia em quintal de casa. } \\ \text { Mordeu a māo de criança de } 6 \text { anos }\end{array} \\ \begin{array}{ccc}\text { Artibeus } \\ \text { lituratus }\end{array} & ? .11 .84 & \begin{array}{l}\text { São Vicente } \\ \text { SP, Brasıl }\end{array} & \begin{array}{l}-2 \text { morcegos em chāo de praça pública capturados por pessoa leiga } \\ \text { (33 anos). Um dos morcegos mordeu o dedo da mäo. Três crianças }\end{array} \\ & & \text { mantiveram contato (nāo determinado) com os morcegos. }\end{array}$

Morcegos Hematófagos

$\begin{array}{ll}\text { Desmodus } & 1964 ? \\ \text { rotundus } & \\ \text { D. rotundus } & 1964 ?\end{array}$

$\begin{array}{lll}\text { D. rotundus } & 16.04 .92 & \begin{array}{l}\text { Viçosa } \\ \text { AL, Brasil } \\ \text { Dontım }\end{array} \\ \text { D. rotundus } & ? .04 .92 & \begin{array}{l}\text { BR. Brasi } \\ \end{array}\end{array}$

AR, Bras $\|$
Guararema - Morcego encontrado no estábulo, durante o dia. SP, Brasil

Santa Branca - Morcego encontrado no estábulo, durante o dia. SP, Brasil
- Morcego encontrado de dia mordendo pescoço de cavalo. Mordeu também a māo da pessoa (20 anos) que tentou manipulá-10.

- Morcego encontrado à noite no chão da varanda da casa de fazenda e incapacitado de vaar, mordeu o pé de criança de 8 anos.

b O menino fol a óblto 32 dias após agressão. Dados cedidos por Celso A. Gonçalves (DIRA-Campinas, SP).

c O homem mordido foi a óbito ca. 3 meses depois. Bıchir, A. 1985. Relatório a respeito de um caso de raiva humana ocorrido em fevereiro de 1985 no DRS-2. Departamento Regional de Saúde do Litoral, Secretaria de Estado da Saúde de São Paulo (relatório não publıcado). Identificaçảo do morcego feita por Celso A. Gonçalves (comunicação pessoal) e confirmada por um de nós (W. Uieda).

d O rapaz foi a tbito 34 dias depois. Dados cedidos por Valmir Costa (Secretaria de Saúde de Alagoas).

e O menino recebeu tratamento sorovacinal e nāo faleceu (W. Uieda, năo publicado). 
casos de raiva humana transmitida por morcegos insetívoros nos Estados Unidos e Canadá, entre 1950 e $1984^{\circ}$, três (30\%) foram devido à manipulação dos morcegos doentes por pessoas leigas.

No Tabela, $13(68 \%)$ dos 19 casos envolvem molossídeos cujas espécies são comuns em áreas urbanas de muitas cidades brasileiras. $\mathrm{Na}$ maior parte das vezes, os casos de raiva detectados em morcegos são individuais e isolados. Um caso típico de surto de raiva em morcegos não hematófagos foi estudado por Bums e Farinacci ${ }^{3}$ em Tadarida brasiliensis (Tabela). No período de um mês, esses citados autores receberam cinco exemplares infectados com o vírus rábico, provenientes de um mesmo local, indicando um surto de raiva numa dada colônia desse quiróptero. Esse surto era aparentemente consequiência de um programa intensivo de aplicação de DDT, iniciado duas semanas antes do aparecimento do primeiro caso ${ }^{3}$. É possível que o inseticida tenha provocado estresse na colônia, diminuindo conseqüentemente a resistência dos morcegos. Assim, os indivíduos que estavam albergando vírus da raiva e sem sintomas aparentes passaram a manifestar a doença. Em termos de controle, isto sugere que deve ser evitado o uso de produtos químicos tóxicos nas populações de morcegos insetívoros, em edificações ou em outros locais.

O fato de colônias de molossídeos do Estado de São Paulo poderem estar albergando vírus rábi-

\section{Referênclas Blbliográflcas}

1. BAER, G.M. Rabies in nonhematophagous bats. In: Baer, G.M. The natural bistory of rabtes. New York, Academic Press, 1975. p. 79-97.

2. BAUER, A.G. \& CRLSIUS, V.A. Isolamento de vírus rábico de morcego insetívoro no Rio Grande do Sul. In: Conferência Anual da Sociedade Veterinária do Rio Grande do Sul, $4^{\mathrm{a}}$, Porto Alegre, 1965 . v.2, p. 189-94.

3. BURVS, K.F. \& FARINACCI, C.J. Rabies in nonsanguivorous bats of Texas. J. Infect. Dis., 97: 211-8, 1955.

4. CONSTANTINE, D.G. Bats in relation to the health, welfare, and economy of man. In: Wimsatt, W.A. Biology of bats. New York. Academic Press, 1970 . v. 2 p. 319-449.

5. CONSTANTINE, D.G. Bat rabies and bat management. Bull. Soc. Vector. Ecol, 4: 1-9, 1979.

6. CONSTANTINE, D.G. Health precautions for bat researchers. In: Kunz, T. H. Ecological and bebavioral metbods for the study of bats. Washington, Smithsonian Inst. Press, 1988. p. $491-528$ co, aparentemente acima dos níveis normais, deve ser considerado na elaboração de estratégias e na execução do controle de morcegos em áreas urbanas. Em situações normais, cerca de $0,5 \%$ dos molossídeos submetidos a exames de raiva estāo infectados ${ }^{1.5}$.

Desse modo, consideramos importante que um programa de controle de morcegos, em áreas urbanas, seja fundamentado em informaçōes bioecológicas desses animais, educação ambiental e saúde pública. $\mathrm{Na}$ Califórnia, cerca de $40 \%$ dos morcegos infectados e detectados anualmente devem se abrigar nos edifícios das regiōes urbanas ${ }^{3}$. Faz-se necessáriao rever trabalho integrado entre profissionais das áreas afins para planejamento urbano sobre edificaçāo e arborização, para reduzir dois dos fatores de crescimento populacional fornecidos abundantemente a esses mamíferos noturnos voadores em áreas urbanas: abrigo e alimento.

\section{Agradecimentos}

Ao Setor de Diagnóstico de Rajva do Centro de Controle de Zoonoses da Prefeitura de São Paulo, à Seção de Raiva do Instituto Biológico e ao Serviço de Diagnóstico de Zoonoses da Faculdade de Medicina Veterinária e Zootecnia da UNESPBotucatu pela realização dos exames de raiva nos morcegos.

7. DELPIETRO, H.; BOEHRINGER, E.G.; FORNES, A. Rabia en murcielagos insectivoros (primer caso en el genero Eumops). Rev. Med. Vet. (Bs.As.), 50(1): 57-61, 1969.

8. FENTON, M.B. Bats. New York, Facts on File, 1992.

9. RODRIGUES, F.A Z.M.P. \& NILSSON, M.R. Isolamento do virus da raiva de morcego insetívoro Molossus obscurus (Geoffroy, 1805), no Estado de Sào Paulo. Arq. Inst. Biol., 42: 193-6, 1975.

10. SILEONI, S.; ROSSETTI, O.; MARQLEZ, A.; MENOYO, A.C.; TORRES, R.A de, Aislamiento de virus rabico de murcielagos insectivoros en Cordoba, Argentina. Bol. Oficina Sanit. Panam., 70: 456-462, 1971.

11. SLGAY, W. \& NILSSON, M.R. Isolamento do vírus da raiva de morcegos hematófagos do Estado de São Paulo (Brasil). Bol. Oficina Sanit. Panam., 60:310-5, 1966

12. TADDEI, V.A.; GONÇALVES, C.A.; PEDRO, W.A.; TADEI, W.J.; KOTAIT, I.; ARIETA, C. Distribuiçăo do morcego vampiro Desmodus rotundus (Chiroptera, Pbyllostomidae) no Estado de 
São Paulo e a raiva nos animais domésticos. São Paulo, Coordenadoria de Assistência Técnica Integral, Secretaria de Agricultura e Abastecimento do Estado de São Paulo, 1991.
13. UIEDA, W.; SILVA, M.M.S.; HARMANI, N.M.S. Quirópteros e raiva: espécies com diagnóstico positivo no Brasil. Arq. Bras. Med. Vet. Zootec, 1995 (in press).

\section{Abstract}

Four rabid bats belonging to three species of Molossidae (one Molossus molossus, one Nyctinomops laticaudatus and two N. macrotis) were captured in the State of S. Paulo, southeastem Brazil. Three of these bats were found during the day in unusual, visible places and the other came flying through a window in the evening. A descriptive table containing data on 19 similar cases, belonging to elght species, is presented and suggests that bats with atyplcal behavior must dearly be suspected of being sick, possibly as having rabies.

Rabies, epidemiology. Chiroptera, microbiology. Rabies viruses. 